\title{
The epidemiology of amoebiasis in Thi-Qar Province, Iraq (2015-2020): differentiation of Entamoeba histolytica and Entamoeba dispar using nested and real-time polymerase chain reaction
}

\author{
Mohammed Hassan Flaih', Ruaa Majid Khazaal', Manar Karem Kadhim², \\ Khwam Reissan Hussein ${ }^{1}$, Falah Abd Bashir Alhamadani ${ }^{3}$ \\ 'Department of Medical Laboratory Techniques, Nasiriyah Technical Institute, Southern Technical University, Nasiriyah, Iraq; ${ }^{2}$ Thi-Qar Education \\ Directorate, Nasiriyah, Iraq; ${ }^{3}$ Bint Al-Huda Maternity and Children Teaching Hospital, Thi-Qar Health Office, Nasiriyah, Iraq
}

\begin{abstract}
OBJECTIVES: The objective of this study was to evaluate the present status of amoebiasis in Thi-Qar Province in southern Iraq, and to determine the presence of Entamoeba histolytica and Entamoeba dispar with nested and real-time polymerase chain reaction (PCR).
\end{abstract}

METHODS: Epidemiological data were obtained from the public health department of the Thi-Qar Health Office (2015-2020). Eighty stool samples were also randomly collected from patients $\leq 12$ year of age with diarrhea at 2 hospitals between the beginning of February 2020 and the end of October 2020. These samples were selected after microscopy to identify the $18 S r R N A$ gene in Entamoeba DNA.

RESULTS: Of the 341,554 cases of intestinal parasitic infections, 38,004 (11.1\%) individuals were recorded as having amoebiasis, which accounted for the highest proportion of infections in 2015 (26.1\%) and the lowest in 2020 (8.1\%). Amoebiasis was distributed among all age groups, with the age group of 5-14 years accounting for the highest proportion (27.3\%). In molecular testing, 42 (52.5\%) out of 80 samples were positive for the $18 S$ rRNA gene (888 bp). Using nested PCR, E. histolytica (439 bp) was detected in $25(31.3 \%)$ samples and E. dispar (174 bp) in $14(17.5 \%)$, while using real-time PCR, E. histolytica and E. dispar were detected in $28(35.0 \%)$ and 15 (18.8\%) samples, respectively.

CONCLUSIONS: Epidemiological data confirmed that amoebiasis is endemic in this province, and is not limited to certain months. Our study confirms the applicability of molecular identification to detect pathogenic and non-pathogenic Entamoeba to prescribe the appropriate drug.

KEY WORDS: Intestinal diseases, Polymerase chain reaction, rRNA gene, Entamoeba histolytica, Entamoeba dispar

Correspondence: Mohammed Hassan Flaih

Department of Medical Laboratory Techniques, Nasiriyah Technical Institute, Southern Technical University, Nasiriyah 64001, Iraq E-mail: moh.alqurayshi@stu.edu.iq

Received: Mar 23, 2021 / Accepted: May 6, 2021 / Published: May 6, 2021

This article is available from: https://e-epih.org/

(c) This is an open-access article distributed under the terms of the Creative Commons Attribution License (https://creativecommons.org/licenses/by/4.0/), which permits unrestricted use, distribution, and reproduction in any medium, provided the original work is properly cited.

(C) 2021, Korean Society of Epidemiology

\section{INTRODUCTION}

Amoebiasis is still considered to be a global health problem that spreads in tropical and subtropical regions [1]. The transmission of amoebiasis in developing countries is usually due to poor sanitation, poor hygiene, and crowded living conditions, whereas it is mostly transmitted in developed countries by people who travel from endemic countries [2,3]. About 500 million people are believed to be with amoebiasis worldwide [4]. Previous studies have estimated that 50 million people contract amoebiasis annu- 
ally and that 100,000 people die from amoebiasis every year $[5,6]$. However, amoebiasis is considered the third-highest cause of death among human parasitic infections $[7,8]$.

Although the genus Entamoeba contains six species (E. coli, E. histolytica, E. dispar. E. moshkovskii, E. bangladeshi, E. hartmanni, and E. poleki) that colonize the human large intestine, only E. histolytica is considered a pathogen that invades the intestinal tract [9]. E. histolytica is an enteric extracellular protozoan that can attach and then destroy epithelial tissue. The most common manifestations accompanying this disease are bloody diarrhea, fever, abdominal pain, colitis, malaise, fatigue, flatulence, and weight loss [10]. It has 2 forms (trophozoites and cysts) in its life cycle. Infection occurs by the ingestion of water or food contaminated with cysts. In the small intestine, trophozoites excyst to develop and colonize the colonic region, and then adhere to the mucosal layer of the large intestines. E. histolytica causes intestinal and extra-intestinal infections [11]. In addition, some trophozoites may be excreted in stool outside the human host, but are not able to survive. The signaling pathways that lead to excystation or encystation are not clearly understood [12]. In extra-intestinal infections, E. histolytica parasites may penetrate the intestine wall to reach the liver through the portal circulation to form hepatic abscesses, which can be fatal if untreated. Abscesses may infect other organs, including the lungs and brain [8].

Previously, microscopic examinations were the only technique used in routine diagnostic laboratories to determine the presence of gastrointestinal parasites in stool specimens [13]. However, traditional diagnostic methods do not discriminate among the causative species of disease [14]. Since E. dispar, E. bangladeshi, and E. moshkovskii are morphologically identical to E. histolytica, molecular techniques have been used to facilitate the identification of $E$. histolytica at the genotype level [8]. Generally, polymerase chain reaction (PCR)-based techniques have higher sensitivity and specificity than microscopic tests [15]. Many studies have widely targeted unique regions of the small subunit ribosomal RNA fragment to diagnose the parasite, as a high copy number provides increased sensitivity [16].

This study was undertaken to determine the prevalence of amoebiasis during a 6-year period in the study area (Thi-Qar Province, Iraq). It also aimed to compare 2 PCR-based techniques (nested and real-time PCR) to determine is more sensitive for the genomes of E. histolytica and E. dispar.

\section{MATERIALS AND METHODS}

\section{Study area and sample collection}

Thi-Qar is a large province in southern Iraq. It is located at $31^{\circ} 14^{\prime} \mathrm{N} 46^{\circ} 19^{\prime} \mathrm{E}$. The total area is $12,900 \mathrm{~km}^{2}$ and it includes approximately 2 million people [14]. It shares internal boundaries with Basrah, Missan, Wassit, and Muthanna Provinces. The capital of the province is Nasiriyah. Thi-Qar Province has a short winter and a very long, hot summer with a decreasing rainfall rate throughout the year [17].
All medical information regarding amoebiasis in Thi-Qar Province for 6 years (from the beginning of January 2015 until the end of December 2020) was taken from patient records at the Public Health Department of the Thi-Qar Health Office, including sex, date, age, and residence area. Direct smears were used to diagnose amoebiasis patients. The molecular studies were conducted at 2 locations: Bint Al-Huda and Mohammed Al-Mosawy Hospitals, from the beginning of February 2020 to the end of October 2020. These hospitals treat children $\leq 12$ years of age. Eighty stool samples were randomly obtained from patients with diarrhea, and then were examined (general stool examination) using microscopy to observe trophozoites and/or cysts in the stool. Each of the 80 samples was kept in a stool container in a refrigerator $\left(-20^{\circ} \mathrm{C}\right)$.

\section{Genomic DNA extraction}

Genomic DNA was extracted from the stool using a stool DNA extraction kit (Bioneer, Daejeon, Korea), according to the manufacturer's protocol. DNA concentration and purity were examined with a Nanodrop spectrophotometer (Thermo Fisher, Waltham, MA, USA). Extracted DNA was stored at $-20^{\circ} \mathrm{C}$ for use in PCR amplification [18].

\section{Nested polymerase chain reaction assay}

Two successive runs with 2 primers (external and internal primers) are involved in the nested PCR technique. A target region within the product of the first run is amplified by the second primer [19]. The $18 S$ rRNA gene was amplified to identify E. histolytica and E. dispar, according to Khairnar \& Parija [20], which included two steps. The extracted DNA was mixed with external primers (E-1 5'-TAA GAT GCA GAG CGA AA-3' and E-2 5'GTA CAA AGG GCA GGG ACG TA-3') for the detection of the Entamoeba genus at $888 \mathrm{bp}$. The nested PCR primers were prepared by IDT Company (Ottawa, ON, Canada). The PCR master mix was prepared according to KAPA2G Robust HotStart Ready Mix $(2 \times)$ PCR kit (Kapa Biosystems, Cape Town, South Africa). The master mix of the first run prepared $4 \mu \mathrm{L}$ of DNA template, $12.5 \mu \mathrm{L}$ of master mix $2 \times, 1.25 \mu \mathrm{L}$ of $10 \mathrm{pmol}$ of each external primer, and $6 \mu \mathrm{L}$ of nuclease-free water. The thermal reaction consisted of initial denaturation at $96^{\circ} \mathrm{C}$ for 2 minutes followed by 30 cycles at $92^{\circ} \mathrm{C}$ for 60 seconds (denaturation), $56^{\circ} \mathrm{C}$ for $60 \mathrm{sec}-$ onds (annealing) and $72^{\circ} \mathrm{C}$ for 90 seconds (extension), and final extension at $72^{\circ} \mathrm{C}$ for 7 minutes. The second run used the same concentration as the first run, except that $4 \mu \mathrm{L}$ of the first run product was added as a DNA template. Amplification was conducted using the following internal primers: EH-1 5'-AAG CAT TGT TTC TAG ATC TGA G-3' and EH-2 5' - AAG AGG TCT AAC CGA AAT TAG-3' to identify E. histolytica (439 bp), and ED-1 5' - TCT AAT TTC GAT TAG AAC TCT-3'and ED-2 5'TCC CTA CCT ATT AGA CAT AGC-3’ to detect E. dispar (174 $\mathrm{bp})$. The thermal conditions of the second-run reaction were the same as the first run except that the annealing was at $48^{\circ} \mathrm{C}$. These products were passed onto an agarose gel (2\%) containing $3 \mu \mathrm{L}$ of 
ethidium bromide. In the electrophoresis room, the tray was fixed and filled with a tris-borate-ethylenediaminetetraacetic acid buffer. A ladder $(5 \mu \mathrm{L})$ was added into the first well, and $10 \mu \mathrm{L}$ of each PCR product was placed into other wells. The electric current was set at $100 \mathrm{~V}$ and $80 \mathrm{~mA}$ for 1 hour. Finally, the electrophoresis product bands were imaged with an ultraviolet transilluminator.

\section{Real-time polymerase chain reaction assay}

The $18 S$ rRNA gene was used to diagnose E. histolytica and E. dispar. Real-time PCR was carried out using the reverse primer (Ehd-88R 5'-GCGGACGGCTCATTATAACA-3') and TaqMan probes for E. histolytica: histolytica-96 T; FAM5' UCAUUGAAUGAAUUGGCCAUUU 3'-BHQ1 and E. dispar: dispar-96 T; HEX5' UUACUUACAUAAAUU GGCCACUUUG 3'-BHQ1 [21]. In real-time PCR, each species was visualized with different-colored filters. The $2 \times$ Kapa Probe qPCR Master Mix kit (Kapa Biosystems) used in the real-time quantitative PCR amplification and the master mix were prepared according to the manufacturer's instructions, using $3 \mu \mathrm{L}$ of genomic DNA, $12.5 \mu \mathrm{L}$ of master mix, $1.5 \mu \mathrm{L}$ of Ehd-88R primer, $1 \mu \mathrm{L}$ of each of the histolytica-96 T and dispar-96 T probes, and $6 \mu \mathrm{L}$ of nuclease-free water. The thermocycler conditions included an initial denaturation step at $95^{\circ} \mathrm{C}$ for 2 minutes, then followed by 40 cycles of denaturation and annealing/extension at $95^{\circ} \mathrm{C}$ and $60^{\circ} \mathrm{C}$ for 15 seconds and 30 seconds, respectively.

\section{Statistical analysis}

In this study, the chi-square test was used to analyze the data in SPSS version 25 (IBM Corp., Armonk, NY, USA). The significance level was set at $\mathrm{p}$-value $\leq 0.05$.

\section{Ethics statement}

The protocol of the current study was received and approved by the Management of the Public Health Department of the Thi-Qar Health Office to analyze anonymized epidemiological information on participating patients. Oral consent was also obtained from participants' parents for collecting and examining the stool.

\section{RESULTS}

\section{Epidemiology}

During the 6-year study period (from the beginning of January 2015 to the end of December 2020), a total of 38,004 (11.1\%) out of 341,554 intestinal parasitic infections were classified as amoebiasis. Patients' age ranged from $<1$ year to 60 years. Of the

Table 1. Demographic data of amoebiasis in relation to sex, age, and residential area during the 6-year study period

\begin{tabular}{lc}
\hline Characteristics & $\mathrm{n}(\%)$ \\
\hline Sex & \\
Male & $18,845(49.6)$ \\
Female & $19,159(50.4)$ \\
Age $(\mathrm{yr})$ & \\
$<1$ & $3,416(9.0)$ \\
$1-4$ & $8,536(22.5)$ \\
$5-14$ & $10,383(27.3)$ \\
$15-45$ & $10,129(26.6)$ \\
$>45$ & $5,540(14.6)$ \\
Residential area & \\
Urban area & $11,636(30.6)$ \\
Rural area & $26,368(69.4)$ \\
\hline
\end{tabular}

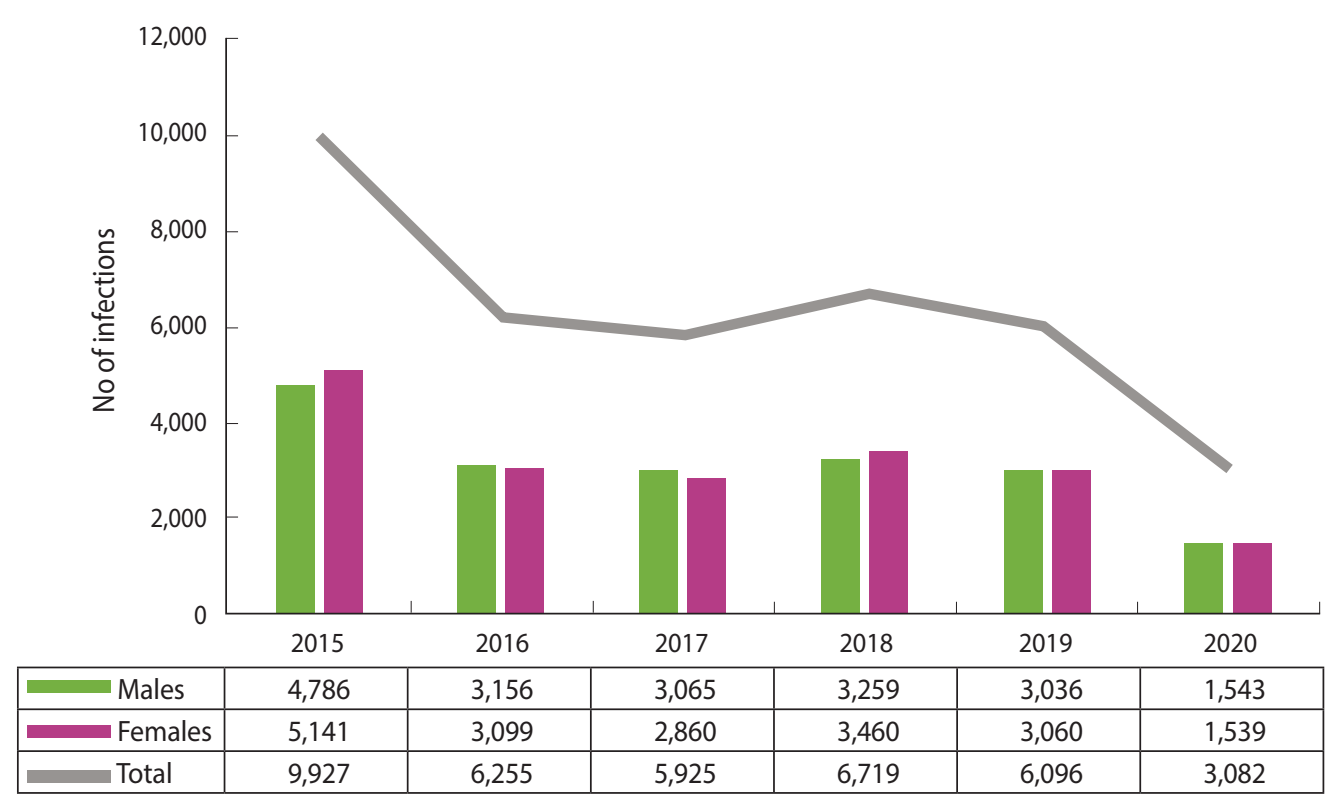

Figure 1. Amoebiasis infections distributed according to sex and year. Values are presented as number. 
38,004 patients, $18,845(49.6 \%)$ and 19,159 (50.4\%) were males and females, respectively (Figure 1). No significant difference according to sex was found $(\mathrm{p}=0.107)$. A significant difference $(\mathrm{p}<0.01)$ in the percentage of amoebiasis among all intestinal parasitic infections was found between 2015 to 2020 , but the overall trend over time showed oscillations $(26.1,16.5,15.6,17.7$, 16 , and $8.1 \%$, respectively).

Table 1 shows that the highest proportion of amoebiasis cases was found in the age group of 5-14 years (27.3\%), while the lowest proportion $(9.0 \%)$ was recorded in the $<1$-year age group. Statistically significant differences were found among age groups $(\mathrm{p}<0.01)$, and the infection numbers decreased with increasing age.

The majority (69.4\%) of infected patients with amoebiasis resided in rural areas, whereas $30.6 \%$ were recorded in urban areas. This difference was statistically significant $(\mathrm{p}<0.01)$. A statistically

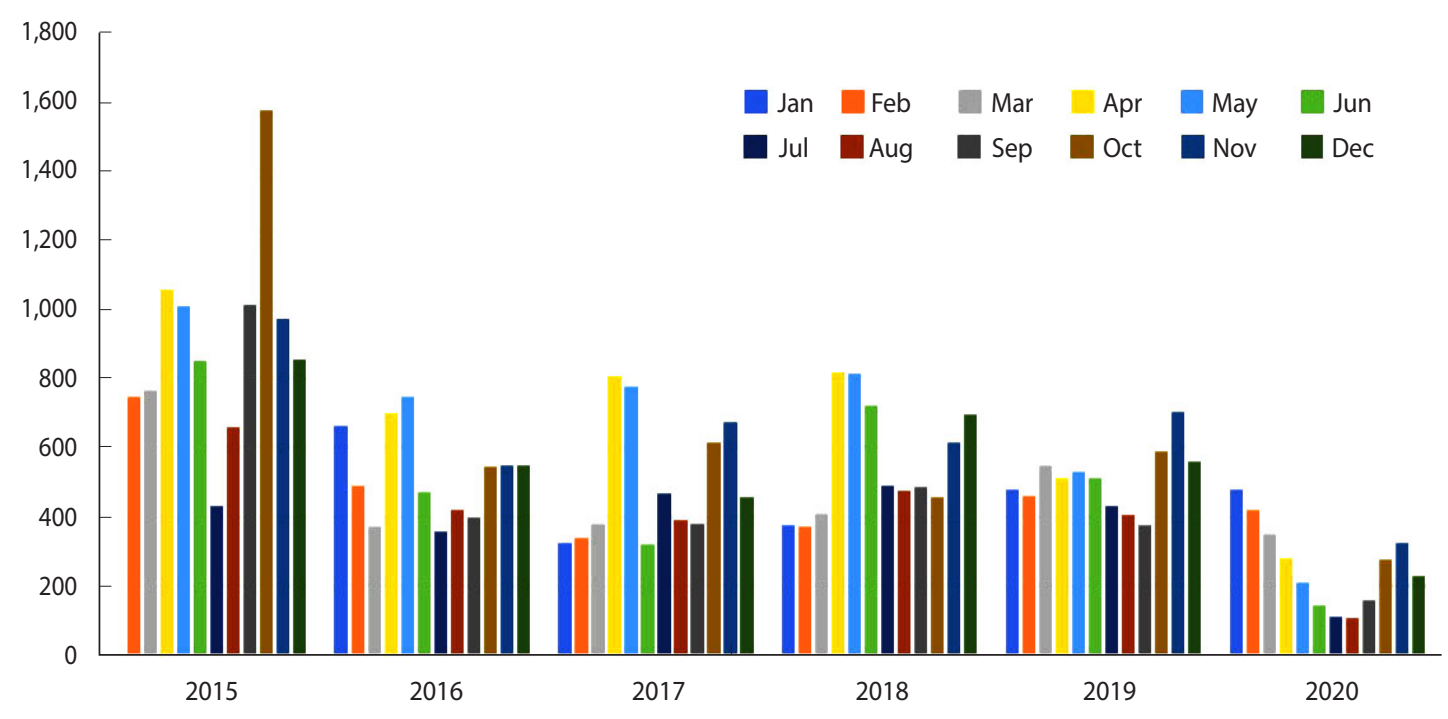

Figure 2. The distribution of amoebiasis according to month and year.
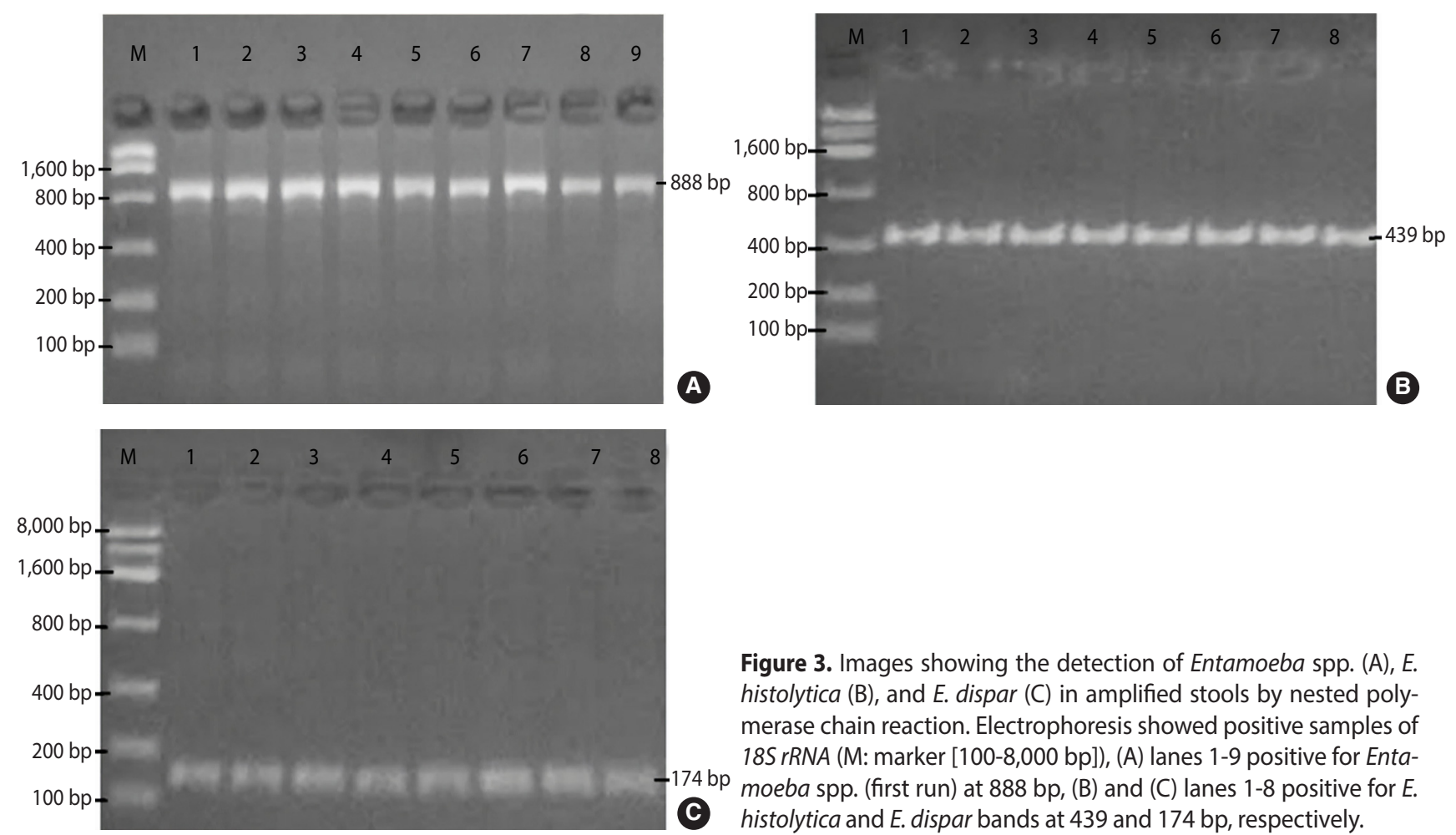

Figure 3. Images showing the detection of Entamoeba spp. (A), E. histolytica (B), and E. dispar (C) in amplified stools by nested polymerase chain reaction. Electrophoresis showed positive samples of 18S rRNA (M: marker [100-8,000 bp]), (A) lanes 1-9 positive for Entamoeba spp. (first run) at $888 \mathrm{bp}$, (B) and (C) lanes 1-8 positive for $E$. histolytica and E. dispar bands at 439 and 174 bp, respectively. 
significant difference was also observed in the month of diagnosis $(\mathrm{p} \leq 0.05)$ (Figure 2).

\section{Molecular characterization}

In nested PCR, the first-run findings showed that 42 (52.5\%) out of 80 samples were positive for the $18 S$ rRNA gene ( $888 \mathrm{bp}$ ) of Entamoeba spp. The 80 samples were divided into 2 equal groups (one was contained trophozoites only, whereas the other included trophozoites and/or cysts); in these 2 groups, 10 samples and 32 samples were positive, respectively. Briefly, the samples that contained cysts were considered suitable for molecular examinations.

Of the 42 samples of the second-run products that were electrophoresed, 25 (31.3\%) were positive for E. histolytica (a 439-bp fragment) and 14 (17.5\%) were positive for E. dispar (a 174-bp fragment) (Figure 3). Three (3.8\%) were classified as Entamoeba spp. (Table 2).

From the 42 positive samples of $18 S$ rRNA gene, E. histolytica and E. dispar were detected in 28 (35.0\%) and 15 (18.8\%) samples by real-time PCR, respectively (Figure 4 ). No statistically significant differences were found between E. histolytica and E. dispar with the 2 techniques that were used.

\section{DISCUSSION}

Epidemiological studies on the prevalence of parasitic intestinal infections in different areas have usually aimed to identify communities at risk and diseases that pose risks to human populations, making it necessary to study infections that threaten human health throughout the world [22]. Several environmental, biological, behavioral, socioeconomic, and health-related factors affect parasitic infections directly or indirectly. The quality of city or village infrastructure, income, occupation, and education level are also important aspects that affect the spread of infection, disease transmission, and mortality [23].

Table 2. Comparison of results of nested PCR and real-time PCR of E. histolytica and E. dispar

\begin{tabular}{|c|c|c|c|c|c|c|}
\hline \multirow{2}{*}{ Entamoeba spp. } & \multicolumn{3}{|c|}{ Real-time PCR } & \multicolumn{3}{|c|}{ Nested PCR } \\
\hline & Trophozoites & Cysts \pm trophozoites & Total, n (\%) & Trophozoites & Cysts \pm trophozoites & Total, n (\%) \\
\hline E. histolytica & 5 & 20 & $25(31.3)$ & 7 & 21 & $28(35.0)$ \\
\hline E. dispar & 4 & 10 & $14(17.5)$ & 5 & 10 & $15(18.8)$ \\
\hline Other & 1 & 2 & $3(3.8)$ & - & - & - \\
\hline
\end{tabular}

$\mathrm{PCR}$, polymerase chain reaction.

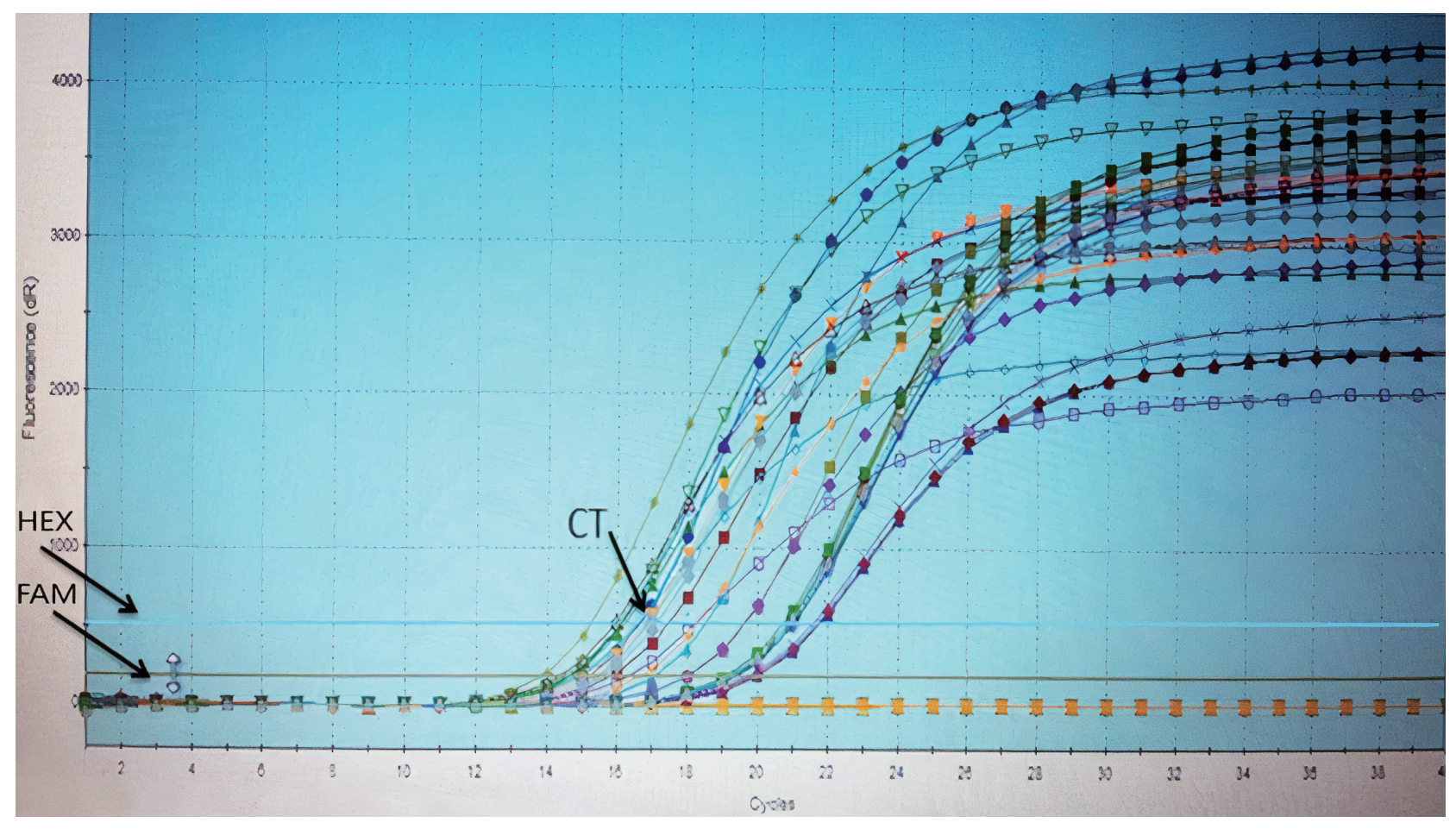

Figure 4. Graph showing the amplification products and the detection limits of the $18 S$ rRNA gene in Entamoeba spp. (E. histolytica and $E$. dispar) using real-time polymerase chain reaction. HEX, hexachlorofluorescein; FAM, fluorescent reporters 6-carboxyfluorescein; CT, cycle threshold. 
In this study, there were 38,004 enrolled patients with amoebiasis in the 6-year study period ( $49.6 \%$ males and $50.4 \%$ females), corresponding to an even distribution by sex. This result aligns with those reported by Al-Damerchi \& Al-Ebrahimi [24] and Hamza et al. [25] in Iraq. The year 2020 had the lowest infection rate during the study period, which may have been due to the coronavirus disease 2019 (COVID-19) pandemic in Iraq, which led people to fear hospitals and health centers. In the current study, the infection rates differed by age, and were highest in the 5-14 age group. Variation in intestinal parasitic infections by age is expected, as daily activities and behavioral habits play an important role in determining the time and type of exposure to the infective stage of the parasite [26]. Our results agree with the findings of several studies, such as those of Saida [22]; Al-Taei [27]; Al-Saqur et al. [28] in Iraq; Nath et al. [7] in India and Al-Dalabeeh et al. [8] in Jordan. The study recorded a higher proportion of infections in rural areas than in urban areas, which is compatible with previous studies, such as those conducted by Nath et al. [7]; Al-Damerchi \& Al-Ebrahimi [24], and Al-Dalabeeh et al. [8]. The proportion of infections by month fluctuated during the 6-year study period, but environmental conditions such as the temperature, drinking water pollution, health services, and nutritional behavior, which are generally considered to vary over time, affect the incidence of parasitic infections [27]. These results are similar to those of Nath et al. [7] and Saida [22].

Microscopic examinations of E. histolytica are often inaccurate and unreliable, especially in samples containing morphologically identical species such as E. dispar, E. bangladeshi, and E. moshkovskii, so molecular tools are useful for the specific identification of Entamoeba spp. [8,29]. In this study, among the 80 stool samples that were microscopically identified as being positive for Entamoeba, 42 were positive for the $18 S$ rRNA gene. Of these samples, 25 and 14 were positive for E. histolytica and E. dispar with nested PCR, respectively, whereas 28 and 15 were found to be positive using real-time PCR. This result aligns with those of other studies, such as those conducted by Mohammed et al. [30], Al-Saqur et al. [28], and Faqe Mahmood \& Mustafa [18]. However, the low results for molecular identification may be due to the lysis of trophozoites resulting from sample storage or due to the presence of other Entamoeba spp. that are morphologically similar to $E$. histolytica and E. dispar [4,20].

In conclusion, epidemiological research provides insights into the incidence and prevalence of a disease according to factors such as sex, endemic areas, temperature, economic activity, and the health environment. This study analyzed amoebiasis, which is considered a health burden and uncontrolled disease in Thi-Qar Province, especially in low-hygienic and poor regions. Although all the reported cases in this study were treated with anti-amoebic drugs, it is thought that many cases of E. dispar infection were treated unnecessarily. This study suggests the need to conduct molecular identification before treatment, and found that both nested and real-time PCR were beneficial for diagnosing Entamoeba spp.

\section{CONFLICT OF INTEREST}

The authors have no conflicts of interest to declare for this study.

\section{FUNDING}

None.

\section{ACKNOWLEDGEMENTS}

The authors thank the Public Health Department of the ThiQar Health Office for their kind assistance, especially Mr. Qasim Aidan Jaber. We would also like to thank the dermatology at Bint Al-Huda and Mohammed Al-Mosawy Hospitals for their help with sample collection.

\section{AUTHOR CONTRIBUTIONS}

Conceptualization: MHF. Data curation: MKK, RMK. Formal analysis: MHF. Funding acquisition: None. Methodology: MHF. Project administration: MHF, KRH, FABA. Visualization: FABA. Writing - original draft: MHF, KRH. Writing - review \& editing: MHF, RMK, KRH, MMK, FABA.

\section{ORCID}

Mohammed Hassan Flaih: https://orcid.org/0000-0001-98246778; Ruaa Majid Khazaal: https://orcid.org/0000-0002-3028-9840; Manar Karem Kadhim: https://orcid.org/0000-0003-2225-061X; Khwam Reissan Hussien: https://orcid.org/0000-0003-4178-7922; Falah Abd Bashir Alhamadani: https://orcid.org/0000-0001-54084711

\section{REFERENCES}

1. Roshdy MH, Abd El-Kader NM, Ali-Tammam M, Fuentes I, Mohamed MM, et al. Molecular diagnosis of Entamoeba spp. versus microscopy in the Great Cairo. Acta Parasitol 2017;62:188191.

2. Ohnishi K, Kato Y, Imamura A, Fukayama M, Tsunoda T, Sakaue $\mathrm{Y}$, et al. Present characteristics of symptomatic Entamoeba histolytica infection in the big cities of Japan. Epidemiol Infect 2004; 132:57-60.

3. Parija SC, Khairnar K. Entamoeba moshkovskii and Entamoeba dispar-associated infections in pondicherry, India. J Health Popul Nutr 2005;23:292-295.

4. Guevara Á, Vicuña Y, Costales D, Vivero S, Anselmi M, Bisoffi Z, et al. Use of real-time polymerase chain reaction to differentiate between pathogenic Entamoeba histolytica and the nonpathogenic Entamoeba dispar in Ecuador. Am J Trop Med Hyg 2019; 100:81-82.

5. Gomes Tdos S, Garcia MC, de Souza Cunha F, Werneck de Mac- 
edo H, Peralta JM, Peralta RH. Differential diagnosis of Entamoeba spp. in clinical stool samples using SYBR green real-time polymerase chain reaction. ScientificWorldJournal 2014;2014: 645084.

6. Saidin S, Othman N, Noordin R. Update on laboratory diagnosis of amoebiasis. Eur J Clin Microbiol Infect Dis 2019;38:15-38.

7. Nath J, Ghosh SK, Singha B, Paul J. Molecular epidemiology of amoebiasis: a cross-sectional study among North East Indian population. PLoS Negl Trop Dis 2015;9:e0004225.

8. Al-Dalabeeh EA, Irshaid FI, Roy S, Ali IK, Al-Shudifat AM. Identification of Entamoeba histolytica in patients with suspected amebiasis in Jordan using PCR-based assays. Pak J Biol Sci 2020; 23:166-172.

9. Parija SC, Mandal J, Ponnambath DK. Laboratory methods of identification of Entamoeba histolytica and its differentiation from look-alike Entamoeba spp. Trop Parasitol 2014;4:90-95.

10. Alyasari HF, Hashim HO, Altaei AH, Al-Shuhaib MB. Identification of serious clinical amebic dysentery cases in the middle Euphrates region of Iraq. J Biol Sci 2019;19:148-154.

11. López-López P, Martínez-López MC, Boldo-León XM, Hernández-Díaz Y, González-Castro TB, Tovilla-Zárate CA, et al. Detection and differentiation of Entamoeba histolytica and Entamoeba dispar in clinical samples through PCR-denaturing gradient gel electrophoresis. Braz J Med Biol Res 2017;50:e5997.

12. Samie A, ElBakri A, AbuOdeh RE. Amoebiasis in the tropics: epidemiology and pathogenesis; 2012 [cited 2021 Jun 3]. Available from: https://www.intechopen.com/books/current-topics-intropical-medicine.

13. Laude A, Valot S, Desoubeaux G, Argy N, Nourrisson C, Pomares $\mathrm{C}$, et al. Is real-time PCR-based diagnosis similar in performance to routine parasitological examination for the identification of Giardia intestinalis, Cryptosporidium parvum/Cryptosporidium hominis and Entamoeba histolytica from stool samples? Evaluation of a new commercial multiplex PCR assay and literature review. Clin Microbiol Infect 2016;22:190.e1-190.e8.

14. Flaih MH, Al-Abady FA, Hussein KR. Phylogenetic analysis of kinetoplast DNA: kDNA of Leishmania tropica in Thi-Qar province, Iraq. medRxiv 2020. doi: https://doi.org/10.1101/2020.10.28 .20220228 .

15. Ögren J, Dienus O, Matussek A. Optimization of routine microscopic and molecular detection of parasitic protozoa in SAF-fixed faecal samples in Sweden. Infect Dis (Lond) 2020;52:87-96.

16. Shahrul Anuar T, M Al-Mekhlafi H, Abdul Ghani MK, Osman E, Mohd Yasin A, Nordin A, et al. Prevalence and risk factors associated with Entamoeba histolytica/dispar/moshkovskii infection among three Orang Asli ethnic groups in Malaysia. PLoS One 2012;7:e48165.

17. AbdulHasan MJ, Hanafiah MM. Assessing water consumption of barley cultivation in Thi-Qar province, Iraq. J CleanWAS 2017; 1:30-34.

18. Faqe Mahmood SA, Mustafa HB. Molecular identification and prevalence of Entamoeba histolytica, Entamoeba dispar and Entamoeba moshkovskii in Erbil City, northern Iraq. Pol J Microbiol 2020;69:1-10.

19. Green MR, Sambrook J. Molecular cloning: a laboratory manual; 2012 [cited 2021 Mar 1]. Available from: https://www.cshlpress. com/pdf/sample/2013/MC4/MC4FM.pdf.

20. Khairnar K, Parija SC. A novel nested multiplex polymerase chain reaction (PCR) assay for differential detection of Entamoeba histolytica, E. moshkovskii and E. dispar DNA in stool samples. BMC Microbiol 2007;7:47.

21. Lau YL, Anthony C, Fakhrurrazi SA, Ibrahim J, Ithoi I, Mahmud R. Real-time PCR assay in differentiating Entamoeba histolytica, Entamoeba dispar, and Entamoeba moshkovskii infections in Orang Asli settlements in Malaysia. Parasit Vectors 2013;6:250.

22. Saida LA. Epidemiological study of intestinal parasites among population of Erbil city, Kurdistan, Iraq. J Raparin Univ 2016;3:75-86.

23. Coulibaly JT, Fürst T, Silué KD, Knopp S, Hauri D, Ouattara M, et al. Intestinal parasitic infections in schoolchildren in different settings of Côte d'Ivoire: effect of diagnostic approach and implications for control. Parasit Vectors 2012;5:135.

24. Al-Damerchi AT, Al-Ebrahimi HN. Detection of major virulence factor of Entamoeba histolytica by using PCR technique. AlQadisiyah Med J 2016;12: 36-45.

25. Hamza DM, Malaa SF, Alaaraji KK. Real-time-PCR assay based on phosphoglycerate kinase gene for detection of Entamoeba histolytica Trophozoites in stool samples in Holy Karbala, Iraq. Med Leg Update 2021;21:1656-1664.

26. Ahmed NM, Al-Niaeemi BH, Dawood MH. Epidemiological and clinical aspects about the endemic intestinal parasites in reviewers of Mosul General hospitals and healthcare centers/Nineveh governorate-Iraq. Eurasian J Biosci 2020;14:6037-6043.

27. Al-Taei AH. The prevalence of intestinal parasite among the attending peoples to Al-Hashimyah hospitals for seven years, Babylon province, Iraq. J Phys Conf Ser 2019;1294:062022.

28. Al-Saqur IM, Al-Warid HS, Al-Qaisi AQ, Al-Bahadely HS. Prevalence of gastrointestinal parasites in Iraq during 2015. In AIP Conf Proc 2020;2290: 020005.

29. Verweij JJ, Oostvogel F, Brienen EA, Nang-Beifubah A, Ziem J, Polderman AM. Short communication: prevalence of Entamoeba histolytica and Entamoeba dispar in northern Ghana. Trop Med Int Health 2003;8:1153-1156.

30. Mohammed F, Taha A, Salama M. Differentiation of Entamoeba histolytica from Entamoeba dispar by nested multiplex polymerase chain reaction. Parasitol United J 2017;10:23-29. 